\title{
A formação política do Brasil segundo Furtado
}

\section{MAURO BOIANOVSKY*}

The political development of Brazil according to Celso Furtado. The article provides a broad view of Celso Furtado's interpretation of the political development of Brazil, spread over his several writings. Furtado's approach was dominated by his analytical effort to understand the effects of the distinct socioeconomic foundations of the United States and Brazil on the development of their respective structures of power. The persistent influence of the Brazilian colonial patriarchal regime was reflected on the fragility of democracy as a political arrangement throughout most of Brazilian history, including the oligarchic republic before 1930. The mismatch between the industrialization process and the inertia of the political system led to unstable populism and eventually to the attempt of military arbitration in 1964.

Keywords: Celso Furtado; political development of Brazil; democracy; United States; populism.

JEL Classification: B31; N46; P16.

\section{INTRODUÇÃO}

Autor do livro clássico Formação Econômica do Brasil, Celso Furtado apresentou também em sua obra elementos do que seria sua interpretação da formação política do Brasil. O presente artigo procura consolidar tais peças analíticas de Furtado enquanto cientista político, distribuídas em vários escritos seus ao longo do tempo. A agenda de pesquisa de Celso Furtado, tanto em economia como também em suas incursões ocasionais em ciência política, foi marcada por sua preocupação em analisar de forma comparativa as experiências históricas do Brasil e dos Estados Unidos. No terceiro volume de sua obra autobiográfica, relembra Furtado (1991, pp. 114-15) que "nenhuma questão me obcecou tanto como esta: por que eles [os Estados Unidos] encontraram o caminho certo, o do desenvolvimento,

\footnotetext{
* Universidade de Brasília. E-mail: mboianovski@gmail.com. Submetido: 22/março/2013; Aprovado: 25/julho/2013.
} 
e nós [o Brasil] o errado, o do subdesenvolvimento?". Parte da resposta pode ser encontrada em seus primeiros estudos sobre as respectivas origens históricas das sociedades americana e brasileira. Enquanto a matriz social dos Estados Unidos é representada pela colonização de povoamento do Norte - que teria engendrado $a b$ initio uma sociedade autogerida e um sistema econômico voltado para a satisfação das necessidades locais - a matriz social brasileira é baseada na escravidão e no sistema de plantações voltado para a exportação. De fato, a reflexão de Furtado sobre a formação política do Brasil não pode ser entendida sem uma prévia discussão de sua visão sobre a experiência democrática norte-americana.

As contribuições de Furtado à ciência política decorrem em larga medida de sua tentativa de interpretar as consequências das distintas matrizes socioeconômicas para a formação das respectivas estruturas do poder nos dois países. O artigo “Trajetória da Democracia na América”, uma das primeiras publicações de Furtado (1946-47), escrita antes mesmo de iniciar na década de 1950 sua vasta obra intelectual como economista, constitui o ponto de partida para investigar a sua reflexão sobre a política na segunda seção. A seguir se discute o tratamento por Furtado do patriarcalismo brasileiro, formulado em dois trabalhos por ele elaborados em Paris em períodos distintos: sua tese de doutorado na Sorbonne em 1948 e sua contribuição ao número especial dedicado ao Brasil da revista Temps Modernes em 1967, editada por J.-P. Sartre. Finalmente, na quarta seção se considera o argumento de Furtado $(1964,1965)$ de que o colapso da experiência democrática brasileira em 1964 decorreu em boa parte da crise causada pela fragilidade do populismo como arranjo político. A produção de Furtado sobre a "teoria da dependência", que abrange aspectos econômicos e políticos, não será tratada aqui por ir além dos limites deste artigo (ver Bresser-Pereira, 2011). Da mesma forma, não será abordada a obra de Furtado como ator político, representada, por exemplo, por seu livro de 1962 A Pré-Revolução Brasileira (ver Vieira, 2007).

\section{DEMOCRACIA E INDIVIDUALISMO}

Como relata Furtado (1985, p. 16) no primeiro volume de sua autobiografia, o ensaio sobre a democracia americana foi publicado na Revista do Instituto Brasil-Estados Unidos após ter vencido o prêmio Franklin D. Roosevelt concedido por aquele instituto. A despeito de sua relevância para o estudo da evolução intelectual de Furtado, e em particular para sua contribuição à ciência política, o ensaio de 1946-47 é raramente mencionado na literatura. Isso se deve provavelmente ao fato de ter sido publicado em fonte de difícil acesso e não ter sido jamais reproduzido em coleções de ensaios do autor. Vera Cepêda (2001) destaca a questão democrática como central à perspectiva política de Furtado, mas omite referências àquele ensaio. Rosa M. Vieira (2007, p. 127, n. 10) observa que a "Trajetória da Democracia" é parte de um conjunto de artigos publicados entre 1944 e 1947, nos quais Furtado examina aspectos diversos da organização da administração publica nos Estados Unidos e no Brasil. Entretanto, não examina em detalhe os argumentos do 
ensaio de 1946-47, e afirma que na obra de Furtado "não se encontrou uma teorização sobre a democracia" (Vieira, 2007, p. 249). O estudo de Roberto P. Silva (2011, cap. 1) sobre o "jovem Furtado" e a administração pública representa importante exceção à carência de discussões sobre o ensaio de 1946-47 na literatura secundária. Como mostra Silva, a reflexão de Furtado sobre a administração pública se insere no contexto de suas atividades como funcionário do DASP (Departamento Administrativo do Serviço Público) no Rio entre 1944 e 1946, quando, além do artigo de 1946-47, publica outros quatro sobre aspectos gerais da administração publica na Revista do Serviço Público.

A autobiografia de Furtado (1985) indica que o ensaio sobre a democracia americana foi escrito em 1946, embora não esteja claro se isso ocorreu pouco antes de voltar à Europa (após ter combatido na Segunda Guerra em 1944-45) ou quando já estava residindo em Paris e cursando a Sorbonne no segundo semestre daquele ano. Como membro da Força Expedicionária Brasileira, Furtado integrara o V Exército dos Estados Unidos na fase final da Segunda Guerra na Itália. O contato com os norte-americanos como oficial de ligação em escola de treinamento intensivo e como paciente em hospitais de campanha deixou forte impressão em Furtado, e contribuíram para a formação de sua "visão" da democracia americana. Como recordaria anos depois,

O espírito democrático que prevalecia naquele exército, a aproximação fácil que se estabelecia entre oficiais e sargentos e mesmo entre estes e os soldados me despertara viva admiração. Logo fui percebendo que todos tinham educação básica similar, procediam de uma sociedade pouco estratificada [...] Logo percebi que o profissionalismo que lhes permitia alcançar altos padrões de eficiência em tudo que empreendiam tinha como causa básica o considerável investimento realizado no fator humano desse país [...] Comemorei o Independence Day de 1945 em um clube de oficiais americanos em Cannes e pude dar-me conta do sentimento que prevalecia entre eles de pertencer a um povo poderoso, generoso e admirado. Como pessoas, os americanos não se pretendiam superiores [...] mas como povo, imaginavam-se guiados pela Providência. (Furtado, 1991, pp. 108-9)

Furtado provavelmente fora exposto a fundamentos de ciência política como parte do curso de Direito realizado na Universidade do Brasil no início da década de 1940. Mesmo tendo optado por doutorado em economia na Sorbonne, matriculou-se no Instituto de Ciências Políticas daquela universidade, onde o curso de André Sigfried lhe abriu os "olhos para as peculiaridades da civilização americana e sua crescente importância no desenho do estilo de vida contemporâneo" (Furtado, 1985, p. 19; 1991, p. 114).

O ponto central do ensaio de 1946-47 é a contradição potencial entre a democracia política e a concentração do poder econômico, que reduz o espaço de ação do indivíduo. Furtado voltaria ao tema nas suas reflexões autobiográficas suscitadas pelo período em que residiu nos Estados Unidos em meados da década de 1960 
como professor e pesquisador na Universidade de Yale, após o golpe militar de 1964 (Furtado, 1991, parte II). Embora o ensaio sobre a democracia na América contenha ampla bibliografia (Max Weber, Karl Mannheim, Ortega y Gasset, Robert Brady, V. Pareto, John Dewey, entre outros), a obra clássica de Alexis de Tocqueville De la Democratie en Amérique publicada em 1835 é conspícua por sua ausência nas referências. Entretanto, Furtado (1991, capítulo intitulado "A dicotomia dos eleitos-excluídos") iria mais tarde referir-se extensivamente a Tocqueville em suas reflexões sobre a sociedade norte-americana, provavelmente por influência de A. Sigfried. Segundo Furtado (1991, p. 75), Tocqueville teria percebido as características que distinguiam a sociedade norte-americana no século XIX: autonomia da gestão municipal, liberdade de consciência e de imprensa, e independência do poder judiciário. Mas, ao mesmo tempo, Tocqueville teria pressentido que a busca de acumulação de riqueza no domínio econômico poderia afetar os valores constituídos na esfera política comunitária. Em particular, a atração da esfera econômica tenderia a afastar da arena política os indivíduos mais talentosos, enquanto a crescente divisão de trabalho causaria aumento da produtividade acompanhado de degradação dos trabalhadores (Furtado, 1991, p. 78; Tocqueville, [1835] 1954, vol. II, livro segundo, caps. XIX e XX).

Furtado (1946-47, pp. 14-15) argumenta que dois fatores fundamentais contribuíram para que as "forças da revolução democrática moderna" encontrassem seu campo ideal de expansão nos Estados Unidos: (i) "os primeiros homens que colonizaram aquele país eram portadores do mais pujante complexo de individualismo que a Europa produziu"; e (ii) "a ausência de estruturas governamentais arcaicas e de estratificação social paralisante das forças de expansão do novo homem foi completada por um fundo móvel duplo constituído pelo continente sem fronteiras e pelas camadas sempre renovadas de população imigratória". Enquanto na Europa o individualismo havia sido parcialmente abortado pelo concomitante desenvolvimento do absolutismo e do Estado (muitas vezes monárquico), a vida puritana na Nova Inglaterra teria levado à experiência de sociedades simples, com associações livres e consequente função secundária do Estado. Tal experiência abriu ao indivíduo um espaço histórico que seria a "moldura da civilização mais democrática que o homem já criou" (p. 9). O atrofiamento do poder central do Estado é acompanhado pelo aumento da importância do governo local, o qual, entretanto, não é um organismo diretor da comunidade nem interfere no "mundo que o individualismo criou para o novo homem", mas sim um mecanismo promotor do bem-estar comunitário na ordem liberal (p. 11).

Furtado ([1978] 2008, pp. 65-66) ampliaria seu argumento sobre a "libertação do indivíduo" como decorrência da revolução burguesa europeia-americana e da consequente primazia do conhecimento e racionalidade acompanhados pela rejeição do dogmatismo e do autoritarismo. Desse modo, a "civilização industrial, que engendrou a revolução burguesa, definiu-se no plano político como um processo de democratização, ou seja, de crescente ligação do princípio de legitimidade à representatividade social do poder".

As colônias que surgiram na faixa que se estende de Nova York a Filadélfia 
contrastavam com as colônias do Sul, baseadas em economia agrícola de exportação e posteriormente escravidão. O espírito comunitário, a prática do autogoverno e o cosmopolitismo da matriz cultural americana conduziriam em meados do século XIX a uma guerra civil entre o espírito democrático e a estratificação social rígida. Entretanto, havia uma contradição inerente na matriz cultural-política americana, decorrente do papel da religião e da ênfase no conhecimento científico.

A civilização americana [...] nasce com o Iluminismo, a busca da ampliação dos horizontes do homem pelo conhecimento empírico do mundo. Em nenhuma parte a escola foi tão cedo universalizada [...] Ao mesmo tempo, essa civilização se nutria de uma visão de mundo fundada no dogma da graça divina, vale dizer, numa antropologia de origem medieval [...] Essa contradição fará da cultura americana um misto de supramodernidade e anacronismo, de pioneirismo e conservadorismo, de universalismo e tribalismo. (Furtado, 1991, p. 77)

Outra contradição, que não é exclusiva da sociedade americana embora nela encontre sua expressão mais forte, reside nas consequências políticas do individualismo econômico engendrado pela Revolução Industrial. Furtado (1946-47, pp. 16-17) utiliza a teoria de administração de F. W. Taylor e H. Fayol para argumentar que a industrialização tende a ser acompanhada pela centralização do processo produtivo na forma de divisão de tarefas em complexas estruturas burocráticas representadas pelas grandes empresas. Tal busca de eficiência e centralização transborda também para o âmbito governamental, num movimento denominado "revolução burocrática moderna", que se contrapõe à antiga significação democrática do governo local. O domínio minoritário dos espaços político e econômico se reflete no que Furtado (p. 15) chama de "homem-massa" em contraposição ao individualismo. A reação a tais "forças antidemocráticas”, segundo Furtado (p. 24), depende da resposta à pergunta:

Como equiparar o homem moderno de maneira a permitir-lhe uma posição de independência diante das forças sociais, comparável à liberdade de ação que caracterizou os construtores da democracia? Em outras palavras, como fazer perdurar o humanismo dentro do regime de massas?

Furtado sugere que a resposta é retomar a preocupação dos pioneiros com o sistema educacional, dessa vez centrado num "novo humanismo" fundamentado no estudo das ciências sociais, o que permitiria a compreensão pelos indivíduos dos mecanismos da sociedade de massas (inclusive macroeconômicos) e a "reconstrução da democracia". Tal desenvolvimento das ciências sociais já estaria ocorrendo então nos Estados Unidos, segundo a avaliação de Furtado na época. Entretanto, anos depois Furtado (1991, p. 92) afirmaria, concordando com J. K. Galbraith e outros economistas norte-americanos, que o problema do controle do poder político e do poder econômico pela cidadania permanecia uma questão não resolvida naquele país, em virtude da ausência de evolução das instituições políticas no sentido de 
capacitá-las ao exercício efetivo de poder na esfera econômica em face das grandes corporações econômicas.

Um dos pontos à la Tocqueville abordados por Furtado (1991, pp. 79-81) em sua autobiografia, mas apenas sugeridos no ensaio de 1946-47, é que a estabilidade institucional norte-americana emergiu não como consequência direta da matriz comunitária daquela sociedade, mas sim como reação aos riscos do "democratismo", ou governo das maiorias. Furtado observa que enquanto a Assembleia Constituinte Francesa de 1789 priorizava a Declaração dos Direitos do Homem, a Convenção Constitucional de 1787 na Filadélfia partia da premissa de que "o homem era a ameaça, sendo necessário, acima de tudo, enquadrá-lo institucionalmente”, o que explicaria por que a Constituição americana trata somente das instituições governamentais, complementada em 1791 pelo Bill of Rights. Segundo Furtado (p. 80), Alexander Hamilton ilustrava bem essa perspectiva ao supor que os homens procuram satisfazer seus próprios interesses e que o melhor que as instituições políticas podem fazer é criar mecanismos para canalizar tais interesses para o bem público. Em particular, para Hamilton a liberdade é baseada na propriedade, pois a estabilização das instituições é importante especialmente para os indivíduos que possuem riqueza para ser protegida. Tal estabilidade dependeria também de um arcabouço que permitisse a neutralização recíproca dos grupos de interesse, como um sistema de forças mecânicas.

Furtado (1991, pp. 80-81) argumenta que "para obter esse extraordinário mecanismo de contrapesos, com o qual os homens haviam sonhado de Aristóteles a Montesquieu", três princípios foram seguidos na história política norte-americana: (i) descentralização federativa, o que facilitaria a disciplina social e diminuiria o risco de subversão popular; (ii) mecanismo de representação, o que por um lado evitaria os problemas da democracia direta ilustrados pela instabilidade grega e por outro daria legitimidade ao poder; (iii) introdução do bicameralismo, concebido por John Adams como uma síntese dos princípios democrático e aristocrático. Juntamente com a independência entre os poderes, esse desenho político assegurava a estabilidade institucional que fundamentou expansão socioeconômica norte-americana. Embora a discussão madura sobre a democracia americana encontrada em Furtado (1991) tenha vínculos claros com o tratamento oferecido no ensaio de 1946-47, a visão em certa medida idealizada deste último deu lugar a uma percepção mais ampla das características centrais das origens e funcionamento do sistema político dos Estados Unidos.

\section{PATRIARCALISMO E PODER}

O capítulo IV, intitulado "O domínio patriarcal e o município brasileiro", da tese de doutorado de Furtado ([1948] 2001), deve ser lido tendo como contraponto a passagem em que Furtado (1946-47, pp. 12-14) trata da organização do governo local americano sob as formas de county e town. Tais esferas administrativas, em particular a town, formaram a base do governo urbano democrático do Norte 
dos Estados Unidos (especialmente na Nova Inglaterra), incluindo a Home-Rule, ou direito das cidades de elaborar suas próprias "cartas". Por outro lado, no Sul latifundiário e escravocrata a concentração de riqueza levaria a um regime patriarcal onde predominava o county em vez da town. De forma similar ao Sul dos Estados Unidos, mas com características próprias, a matriz da estrutura sociopolítica brasileira, afirma Furtado ([1948] 2001, p. 165) citando o livro clássico de Caio Prado Jr. (1945), era baseada no domínio patriarcal colonial.

O domínio patriarcal, com sua primazia econômica, administrativa e religiosa, implicava o esvaziamento do centro urbano. A independência política em 1822, ao invés de diminuir tal influência, tendeu a reforçá-la mesmo após a criação do município como divisão política territorial. Persistiu a supremacia do domínio patriarcal, "que fará do município seu simples valet" ([1948] 2001, p. 167). Furtado atribui tal fenômeno ao fato de o município brasileiro ser uma divisão territorial arbitrária, que lembra em certa medida o county americano como unidade administrativa no sul daquele país. Entretanto, enquanto nos Estados Unidos a influencia administrativa e política patriarcal diminuiria significativamente após a Guerra da Secessão, no Brasil o município persistiria apenas como uma "expressão exterior" da verdadeira célula da sociedade definida pelo patriarcalismo, com fortes consequências para a vida política brasileira.

A inexistência de interesses comuns que liguem os domínios semiautônomos e a tendência ao mandonismo resultante da herança escravista dificultam qualquer entendimento ou colaboração entre os senhores patriarcais. Por outro lado, esse isolamento de grupos semiautônomos fechará o caminho à formação de uma mentalidade política e de uma consciência de coletividade. (Furtado, [1948] 2001, p. 169)

Aproximadamente duas décadas após seu doutorado na Sorbonne, Furtado retorna àquela instituição, dessa vez como professor de desenvolvimento econômico. A convite de Jean-Paul Sartre, organiza número especial da revista Temps Modernes, para o qual contribui com ensaio em que retoma a perspectiva histórica sobre a evolução do sistema político brasileiro em longo prazo. Em vez do Brasil colônia, o foco agora é o período republicano. Entretanto, no inicio da fase republicana em 1889 e mesmo com a abolição da escravatura um ano antes, a estrutura sociopolítica brasileira era ainda definida, a partir de suas bases coloniais, pelo grande domínio agrícola ligado ao comércio exterior. Tal "oligarquia feudal" constituía uma "forma extremada de descentralização do poder político", onde "prevaleciam as relações pessoais" e as "normas jurídicas vindas de fora somente penetravam na medida em que se conciliavam com a vontade do chefe local" (Furtado, [1967] 1968, p. 3). O papel do Estado nacional nesse contexto era limitado à manutenção da unidade nacional, que era a própria justificativa da monarquia como regime político.

Alguns anos depois, em contribuição ao colóquio sobre história quantitativa do Brasil realizado em Paris em outubro de 1971, Furtado (1973, pp. 25-26) retoma 
a questão da preservação da unidade nacional na América lusitana após a independência, em contraste com a divisão da América hispânica em vários países. "Quando se considera a diversidade de interesses econômicos das diferentes regiões do país e as dificuldades de comunicação terrestre e marítima, não se pode deixar de se surpreender com a preservação da unidade nacional." O primeiro fato assinalado por Furtado para explicar tal fenômeno foi o papel de liderança exercido por "funcionários coloniais" no movimento de independência do Brasil, que aponta para a conexão próxima entre a Coroa e o aparato burocrático que administrava o país nos primeiros anos após a independência. Além disso, a classe fundiária, que desempenhava papel de importância crescente na economia, tinha um "horizonte de reflexão" bem mais restrito que os funcionários coloniais que estavam se tornando homens de Estado. "Não se pode exagerar a heterogeneidade da classe fundiária e a falta de articulação que existia entre os grupos fundiários de diferentes regiões. Exceto pela escravidão e pelo tráfico clandestino de africanos que os unia, os vínculos entre as três ou quatro principais regiões permaneceram muito frágeis para justificar a aceitação de uma administração central cuja lentidão e falta de sensibilidade aos interesses específicos locais ultrapassavam os limites do razoável.”

A compreensão do "sistema de poder" que se estrutura no Brasil após a independência depende, segundo Furtado (1973), da consideraração um terceiro fator, além das classes burocrática e fundiária. Tal fator é a "quase inexistência de uma burguesia mercantil nativa, classe que desempenhara papel decisivo na América hispânica, tanto nas guerras de independência como na fase de formação dos novos estados nacionais" (ver também Furtado, 1969, cap. 3, seção "Formação dos Estados Nacionais"). O comércio exterior brasileiro era dominado por comerciantes portugueses e ingleses, que também tinham papel importante no comércio doméstico, especialmente nas principais cidades. Assim, as múltiplas revoltas que ameaçavam o poder central após a independência frequentemente tomavam a forma de "chauvinismo antiportuguês". Desse modo, pode-se imaginar que "se a burguesia mercantil local fosse nativa como nos países da América hispânica, uma aliança regionalista e nativista com a classe fundiária contra o poder central teria tido lugar. Nessa hipótese, as forças centrífugas teriam certamente predominado antes que que a região cafeeira - o eixo São Paulo-Minas Gerais — pudesse impor sua hegemonia”.

Com a instalação da República oligárquica controlada pelos cafeicultores, como observa Furtado ([1967] 1968), o governo central passaria a desempenhar papel relevante na esfera econômica, particularmente em conexão com o financiamento da imigração e da defesa dos preços do café. Paradoxalmente, como observa Furtado, tal transformação nas funções do governo central se deu através de descentralização federal e aumento de poder dos Estados cafeeiros.

Outra dimensão importante da evolução sociopolítica brasileira destacada por Furtado no período foi a ascensão da classe militar no cenário político, atribuída à modernização das Forças Armadas durante os conflitos fronteiriços sul-americanos, e ao crescimento da população urbana e consequente formação de grupos de classe média. A incorporação de tais grupos com suas ideias liberais à vida política brasileira, em choque com a aliança formada pelos grupos semifeudais nordestinos 
e a nova classe agrícola-exportadora do Sudeste constituía fator de instabilidade da República oligárquica entre 1890 e 1930. É nesse contexto que as Forças Armadas foram transformadas pelos políticos de classe média em instrumento de ataque à oligarquia, a qual resistiu sem concessões significativas até 1930, quando a economia do café foi profundamente abalada pela crise econômica mundial e a fase de industrialização por substituição de importações teve inicio. As mudanças ocorridas com a Revolução de 1930, como a abertura do processo político aos grupos de classe média no marco de uma democracia formal com sufrágio universal, levariam à ampliação do processo político às massas urbanas.

O período que se inicia em 1930 e vai até 1964 é marcado, segundo Furtado (p. 10), pelo esforço em atingir um equilíbrio entre a democracia formal demanda pela classe média e o controle do poder pela oligarquia fundiária. Ao invés de equilíbrio, o que se verificou, entretanto, foi a instabilidade do sistema de poder decorrente da tensão entre, de um lado, o Parlamento eleito pela oligarquia rural e, de outro, o Presidente da República, portador de mensagens de modernização ansiadas pelas massas urbanas. A aceleração do crescimento econômico e da industrialização na década de 1950 foi acompanhada pela substituição, no primeiro plano do processo político, do conflito entre a oligarquia e as classes médias urbanas pelo confronto entre o ideário liberal e as pressões vindas das massas. Juntamente com o populismo que se instalara na política brasileira desde os 1930, tais transformações levariam a uma mudança essencial no papel das Forças Armadas no sistema de poder, como discutido a seguir.

\section{POPULISMO E AUTORITARISMO}

O surgimento do populismo no Brasil, como argumenta Furtado, foi consequência da forma como se deu a revolução política iniciada em 1930. A necessidade de reformas profundas, aspiradas pelas massas com a implantação do sufrágio universal, veio à tona quando o exercício de democracia formal de inspiração liberal era ainda frágil e incipiente.

Frustrou-se, portanto, o projeto de criação de uma República liberal, na qual os grupos de classe média representassem a frente progressista, compartilhando o poder com os grupos oligárquicos, médiante um sistema de representação qualificada que conservasse as massas urbanas sob uma tutela similar à que vinha prevalecendo com respeito às massas rurais. $\mathrm{O}$ atraso e o tumulto com que se realizou a revolução liberal deixou a porta aberta à passagem das massas urbanas, abrindo a era do populismo. (Furtado, [1967] 1968, p. 10)

A crise da oligarquia cafeeira após 1929 criara um "vazio de poder" e abrira um processo de transformação do Estado nacional. A aliança estabelecida por Getulio Vargas entre parte significativa da classe política tradicional e as forças 
armadas permitiu a instauração do "Estado novo com um mínimo de modificações na estrutura tradicional de poder" (Furtado, 1972, p. 21). O poder central se consolida entre 1930 e 1937, com certa autonomia em relação aos grupos econômicos tradicionais. As eleições urbanas eram decididas por massas não estruturadas sob lideranças "improvisadas ou oportunistas". Assim, o populismo decorria, por um lado, do atraso na introdução da democracia formal — que impedira as classes médias de introduzirem gradualmente um sistema de controle das massas urbanas — e, por outro, da resistência da classe média e da oligarquia à organização de tais massas em movimentos autênticos de expressão de suas demandas. O resultado foi a inibição da formação de consciência de classe acompanhado pelo paternalismo e corrupção.

De forma mais geral, a dinâmica das estruturas socioeconômicas duais subdesenvolvidas, ao contrário das economias industrializadas desenvolvidas, não é condicionada essencialmente pela luta de classes entre trabalhadores e capitalistas. Os conflitos internos da classe dirigente tornam o comando do Estado extremamente importante e fazem com que o processo político tenda a se dar na forma de uma luta pelo poder entre os grupos que constituem a classe dominante. Ao mesmo tempo, a falta de consciência de classe dos trabalhadores os torna influenciáveis pelas ideologias das classes dirigentes, conhecidas como "populismo". Como observa Furtado (1964, p. 86), tais ideologias são aparentadas ao que se denominou no século XIX "socialismo utópico", caracterizado por "acenar com formas de distribuição do produto social sem preocupar-se com a organização da produção".

O populismo no Brasil seria assim uma manifestação do descompasso entre o ritmo do crescimento econômico - e as consequentes mudanças na estrutura socioeconômica - e a inércia do sistema de instituições políticas. Tal descompasso decorreria da ausência de uma ideologia industrialista dominante no plano político, devido ao fato do processo de industrialização ter ocorrido sem antagonismo aberto com os grupos oligárquicos rurais, ao contrário do modelo clássico de desenvolvimento capitalista. Esta é uma das teses centrais do ensaio de Furtado (1965, p. 137) "Obstáculos políticos ao crescimento econômico no Brasil" — uma reflexão sobre os determinantes do golpe militar de março de 1964 escrita em novembro daquele ano em Yale - provavelmente sua contribuição mais conhecida na área de ciência política. A lenta modernização institucional do sistema político brasileiro deve ser atribuída a essa ausência de uma marcante presença dos industriais na arena política. Desse modo, as constituições políticas, juntamente com o sistema federativo - que dava ao Senado e consequentemente aos pequenos estados agrícolas uma fatia significativa do poder legislativo - , possibilitavam a manutenção de parte importante da antiga influência política da oligarquia rural. Por outro lado, o pacto com as massas urbanas seria condição necessária, em todo o período do pós-guerra, para o domínio do poder executivo. Resultava daí um conflito dentro da Presidência da República entre a subordinação ao marco constitucional e a fidelidade à plataforma eleitoral. O pacto populista é intrinsicamente problemático, pois a própria heterogeneidade das massas urbanas leva a compromissos contraditórios ou disfuncionais. 
Ao contrário dos movimentos políticos que se apoiam nos interesses de uma classe ou de grupos com objetivos definidos, o populismo pretende dialogar com massas heterogêneas, prometendo-lhes a satisfação para as aspirações mais imédiatas, sem qualquer preocupação com as consequências que daí poderiam advir a mais longo prazo. Por esta razão, todo grupo que atua organicamente [...] tende a conflitar com os movimentos populistas. No Brasil esse conflito tem assumido variadas formas e constitui o fundo da instabilidade política que tem caracterizado o pais em toda a fase de industrialização. (Furtado, 1965, p. 141)

De modo geral, as circunstâncias que envolvem o populismo em países subdesenvolvidos favorecem golpes de Estado por lideranças de minorias dentro das classes dirigentes, ensejando o surgimento de ditaduras cuja finalidade é consolidar a posição da classe dirigente e desse modo reduzir a importância do povo como massa de manobra. Como argumenta Furtado (1964, p. 89), tal consolidação pode passar também pela tentativa de promoção do prestígio do ditador no seio da massa através de propaganda e concessão parcimoniosa de favores. Alternativamente, se o ditador não consegue apoio dentro da própria classe dirigente para consolidar-se, transplanta para o regime ditatorial as técnicas populistas. Não foi o que aconteceu no Brasil com o golpe militar de 1964.

Durante a era da República oligárquica até 1930 as Forças Armadas tinham desempenhado papel essencialmente político voltado para a modernização da sociedade. Não teria sido esse o caso no período da República liberal, quando a pressão no sentido da modernização institucional se dava pelos canais da política, abrindo a porta do "reformismo institucional". Segundo Furtado ([1967] 1968, p. 12), "foi o temor de que essa porta se ampliasse demasiadamente rápido que levou o pânico à classe dirigente, a qual apelou para as Forças Armadas a fim de que estas desempenhassem agora o papel de gendarme do status quo social, cuja preservação passava a exigir a eliminação da democracia formal”. O fato de as Forças Armadas terem tido em 1964 um papel oposto àquele desempenhado algumas décadas antes pode ser, assim, explicado pela modificação ocorrida no papel da classe média. Entretanto, como argumenta Furtado (p. 13), deve ser entendido também como decorrência do surgimento da doutrina dos "objetivos nacionais" e do "poder nacional" desenvolvida gradualmente a partir do término da Segunda Guerra Mundial no novo contexto internacional da guerra fria. Dessa forma, o fim do experimento democrático-populista brasileiro ocorre através da arbitragem militar.

O conflito profundo que existe entre as massas urbanas, sem estruturação definida e com liderança populista, e a velha estrutura de poder que controla o Estado, permeia todo o processo político do Brasil atual [...] Esse conflito de poder entre os líderes populistas e a classe dirigente ocupa o centro da luta política e torna impraticável a consecução de qualquer programa coerente por parte daqueles que ocasionalmente dirigem o país [...] A existência de um conflito fundamental que põe em 
xeque o próprio funcionamento das instituições básicas, cria condições favoráveis à arbitragem militar, conforme ocorreu recentemente no Brasil. Essa arbitragem em si não elimina as causas do conflito, mas cria condições para a ruptura do impasse. (Furtado, 1965, pp. 143-44)

Em principio, tal arbitragem poderia servir para consolidar a estrutura tradicional de poder ou forçar mudanças nessas estruturas. Entretanto, estava claro para Furtado então que a hipótese de um populismo militar no Brasil era altamente improvável, e que a preservação do status quo com o fim da democracia seria o caminho a ser seguido. Além disso, como observa Furtado (1972, p. 34), o frágil equilíbrio populista introduzido por Vargas teria dado lugar após 1964 ao deslocamento da classe política e à ascensão do "grupo industrial" (e da "tecnocracia") como elemento hegemônico do sistema nacional de poder. O processo de redemocratização a partir de meados da década de 1980 é visto como consequência das transformações na relação entre Estado e sociedade (Furtado, 1989). As forças políticas que originalmente sustentaram a ascensão dos militares ao poder eram heterogêneas e, com o tempo, perderam influência. A lógica do regime autoritário passou a ser baseada, por um lado, na ação ampla e indiscriminada do Estado na esfera econômica e, por outro, na negligência das suas responsabilidades na esfera social. A crise do modelo de crescimento a partir da década de 1970, acompanhada pela instabilidade macroeconômica, teria provocado a deterioração da credibilidade e eficácia do Estado autoritário, culminando com sua rejeição crescente pela classe política (sobre o lugar do Estado na obra de Furtado como um todo, ver Francisco de Oliveira, 1997, e Cepêda, 2001).

\section{DISCUSSÃO}

Enquanto cientista político, Celso Furtado ofereceu um esforço de interpretação das diferentes experiências com a democracia no Brasil e nos Estados Unidos numa perspectiva histórica, uma abordagem comum às contribuições do autor em economia. Em particular, fica clara a relevância da herança colonial para entender as dinâmicas divergentes dos dois países, nos planos econômico e político (ver Boianovsky, 2009, para a noção de persistência de longo prazo das instituições em Furtado e sua comparação com Douglass North). Apesar de fazer uso de conceitos da teoria e historia econômica, Furtado não incorre na prática do economista como “imperialista social”, seja em termos marxistas ou neoclássicos.

A leitura feita por Furtado de aspectos da formação política do Brasil não passou despercebida de cientistas políticos brasileiros, embora às vezes de forma crítica. Wanderley Guilherme dos Santos (2003, pp. 173-79), por exemplo, considera Furtado (1965) a melhor ilustração do paradigma clássico da análise social e política brasileira. Segundo Santos, tal paradigma, embora consistente em sua descrição das variáveis macroeconômicas e macrossociais, peca por suas inferências políticas. Assim, Furtado nunca teria demonstrado que o Legislativo, mesmo com 
a maioria de seus membros provenientes de áreas rurais, foi sistematicamente contrário às propostas modernizadoras do Executivo (e.g., criação da Petrobras e implementação do Plano de Metas). A estabilidade do governo Kubitschek tampouco teria sido satisfatoriamente explicada. Santos sugere que Furtado deixa de lado um conjunto de variáveis estritamente políticas necessárias para explicar o episódio de 1964, que não deve ser interpretado apenas em termos das tendências econômicas e sociais de longo prazo.

Por outro lado, Francisco Weffort ([1965] 1978, [1967] 1968), em seus estudos sobre populismo no Brasil, concorda essencialmente com a perspectiva de Furtado na análise daquele fenômeno, especialmente quanto ao papel do surgimento das massas urbanas. Entretanto, como Furtado (1965, p. 141) refere-se à versão preliminar de 1964 de Weffort ([1965] 1978), escrita quando ambos estavam em Santiago do Chile, é mais provável que tenha ocorrido uma interação entre os dois autores. Embora Santos e Weffort sejam representativos da pesquisa brasileira em ciência política, persiste o fato de que os escritos de Furtado na área - especialmente o confronto sempre subjacente entre as experiências brasileira e norte-americana - permanecem pouco estudados por economistas, historiadores e cientistas políticos. A leitura atenta da formação política brasileira sugerida por Furtado fornece novas perspectivas para a interpretação de sua obra como um todo.

\section{REFERÊNCIAS BIBLIOGRÁFICAS}

Boianovsky, M. 2009. Furtado, North and the New Economic History. Economia. 10: 849-66.

Bresser-Pereira, L.C. 2011. From national-bourgeoisie to the dependency interpretation of Latin America. Latin American Perspectives. 38: 40-58.

Cepêda, V.A. 2001. O pensamento político de Celso Furtado: desenvolvimento e democracia. In $A$ grande esperança em Celso Furtado, org. por L.C. Bresser-Pereira e J.M. Rego. São Paulo: Editora 34.

Furtado, C. 1946-47. Trajetória da Democracia na América. Revista do Instituto Brasil-Estados Unidos. 4-5 (10-12): 5-27.

Furtado, C. [1948] 2001. Economia colonial no Brasil nos séculos XVI e XVII. São Paulo: Hucitec e ABPHE.

Furtado, C. 1962. A Pré-Revolução Brasileira. Rio de Janeiro: Fundo de Cultura.

Furtado, C. 1964. Dialética do Desenvolvimento. Rio de Janeiro: Fundo de Cultura.

Furtado, C. 1965. Obstáculos políticos ao crescimento econômico do Brasil. Revista Civilização Brasileira. 1: 129-45.

Furtado, C. [1967] 1968. Brasil: da República oligárquica ao estado militar. In Brasil: Tempos Modernos, org. por C. Furtado. Rio de Janeiro: Paz e Terra. Originalmente publicado em Les Temps Modernes, \# 257.

Furtado, C. 1969. Formação econômica da América Latina. Rio de Janeiro: Lia Editora.

Furtado, C. 1972. Análise do 'modelo' brasileiro. Rio de Janeiro: Civilização Brasileira.

Furtado, C. 1973. Analyse économique et histoire quantitative. In L’Histoire Quantitative du Brésil de 1800 a 1930, pp. 23-26. Paris: Editions du Centre National de la Recherche Scientifique, Colloques Internationaux du Centre National de la Recherche Scientifique, \# 543.

Furtado, C. [1978] 2008. Criatividade e dependência na civilização industrial. São Paulo: Companhia das Letras.

Furtado, C. 1985. A Fantasia Organizada. Rio de Janeiro: Paz e Terra. 
Furtado, C. 1989. Transition vers la démocratie au Brésil. Cahiers du Brésil Contemporain. \# 6: 3-8. Furtado, C. 1991. Os Ares do Mundo. Rio de Janeiro: Paz e Terra.

Oliveira. F. 1997. Viagem ao olho do furacão: Celso Furtado e o desafio do pensamento autoritário brasileiro. Novos estudos CEBRAP. \# 48: 3-19.

Prado Jr., C. 1945. Formação do Brasil Contemporâneo (Colônia). São Paulo: Brasiliense.

Santos, W.G. 2003. O cálculo do conflito: estabilidade e crise na política brasileira. Belo Horizonte e Rio de Janeiro: Editora UFMG e IUPERJ.

Silva, R.P. 2011. O jovem Celso Furtado: história, política e economia. Bauru (SP): EDUSC.

Tocqueville, A. de. [1835] 1954. Democracy in America, tr. por H. Reeve e org. por P. Bradley, 2 vols. New York: Vintage Books.

Vieira, R.M. 2007. Celso Furtado: reforma, política e ideologia (1950-1964). São Paulo: Educ.

Weffort, F.C. [1965] 1978. Estado e Massas no Brasil. In F.C. Weffort. O populismo na política brasileira, cap. II. Rio de Janeiro: Paz e Terra.

Weffort, F.C. [1967] 1968. O populismo na política brasileira. In Brasil: Tempos Modernos, org. por C. Furtado. Rio de Janeiro: Paz e Terra. Originalmente publicado em Les Temps Modernes, \# 257. 